\title{
RESEARCHERS' PERSPECTIVES ON IMPACT OF RESEARCH \& INNOVATION: A STRUCTURAL TOPIC MODEL APPROACH TO COST ACTION PARTICIPANTS
}

\author{
ELWIN REIMINK \\ DOI: $10.22163 /$ fteval.2019.340
}

\section{ABSTRACT}

$\mathrm{T}$ he concept of "societal impact" has in the recent decades started to play a defining role in the (political) debate on the position of $R \mathscr{C l}$ and science funding. In this paper, we add to this debate by exploring researchers' perspectives on the impact of their participation in research networks. We discover that these perspectives can differ between researchers in different roles and career stages, and that these perspectives do not always correspond with "linear" perspectives on societal impact. We conclude that impact assessment might benefit from a more comprehensive focus, with an equal focus on defining project elements.

\section{INTRODUCTION}

The last decennia have seen somewhat of a shift in the relationship between science and society (see Mostert et al., 2010; Bornmann, 2013). There have been several different ways to describe this shift, each with its own particular focus: for example, the "Triple Helix" model focusses on shifting institutional arrangements in knowledge production (Leydesdorff and Etzkowitz, 1998; Etzkowitz and Leydesdorff, 2000). Meanwhile, "Mode 2 knowledge production" sees a paradigm shift amongst the principal actors of knowledge production (Gibbons, 2000; Hessels and van Lente, 2008), while "post-normal science" focusses on the somewhat broader question of a shifting relationship between science and society (Ravetz, 1999). While the respective perspectives of these approaches - as well as their envisaged consequences - differ, they all have in common that they question the traditional role of science as solely focussed on scientific production. Summarizing: the "old" idea of science as relatively isolated from society-at-large and as a linear producer of scientific output is replaced by a somewhat "messier" model of science having a deeper interaction with other parts of society.

This shift in perspective has not only been extensively discussed in the "science on science", but has also seen extensive follow-up in policymaking, notably through the idea of "societal impact" (Bornmann, 2013). Traditionally, "impact" in research was perceived by the community as focussed on science: hence the term "impact factor" and related metrics, like the h-index (Hicks et al., 2015). Yet, as some authors argue, this might leave us with research which is not necessarily the most useful to all societal stakeholders. As Nightingale and Scott (2007, pp. 543) put it: "Long-term changes in knowledge production can produce mismatches between the research society requires and the research society produces". Moreover, the "traditional" perspective with a great emphasis on scientific metrics has also seen validity issues, for example concerning self-citation (e.g. Fowler and Aksnes, 2007).

The concept of societal impact comes, however, with its own particular issues. First, there is no particular encompassing definition of societal impact which goes beyond the definition that societal, economic or ecological goals are (ultimately) served by the proceedings of research. Moreover, when stakeholders from different backgrounds are specifically asked, they appear to have very different concepts in mind concerning societal impact (Van der Weijden et el., 2012). Second, and partially a consequence of the first issue, there is no structured way of measuring societal impact which goes beyond case studies, either in a comparative or in a stand-alone form (e.g. Bell et al., 2011). These two related limitations have consequences for the role of impact in the daily practice of research, especially where it concerns research evaluation. Societal impact (or just "impact") has come to play a major role in the evaluation of proposals of research projects (Holbrook and Frodeman, 2011). Yet, due to a lack of standards concerning what "impact" actually implies, there is a threat that evaluators will struggle to hold descriptions of (potential) impact in research proposal to a uniform yardstick. Similar problems of definition and measurement can complicate ex post evaluation of the success and impact of research projects.

Two broad types of potential solutions to this lack of both conceptualisation and measurement of "societal impact" have been proposed. A first strain of thinking emphasises the innate link between science and societal values. In other words: science is not funded by the public for the very sake of performing science, but rather because ultimateIy, science serves societal goals. Hence, these societal goals should be debated and ultimately pronounced, and "societal impact" should, as a consequence, be measured as the extent to which scientific programs contribute to these goals. This "public values" perspective proposes a strong conceptualisation of societal impact, based upon values, and deduces the measurement from this concept (Bozeman and Sarewitz, 2005; Sarewitz and Pielke, 2007). 
A second strain of thinking starts, instead, from research itself. This perspective emphasises the diversity of the field of science and, as a result, the complexity of formulating concepts of impact which are both inclusive and concrete. Instead, this perspective argues that all forms of societal impact start with the proliferation and dissemination of researchers' knowledge to a wider audience. This mechanism is defined as "productive interactions" by Spaapen and van Drooge (2011) and as "research uptake" by Morton (2015). While research interactions are not a sufficient condition for impact, they are arguably a necessary condition: if research remains completely isolated from the broader (scientific or societal) community, it cannot be applied to the problems it might be supposed to tackle. We can formulate this as follows in a single sentence: the more research interactions take place, the more pathways to impact, previously blocked by a lack of cooperation and/or shared knowledge, are opened up. Moreover, the nature of these interactions can tell us something about the (potential) ultimate impacts caused by the interactions (De Jong et al., 2014).

In this paper, we look at impact from the second, "bottom-up", perspective. We ask ourselves how "interactions" in research and innovation and their concrete benefits are perceived by the researchers and research community themselves.

\section{COST ACTIONS}

To study the phenomenon of "productive interactions" from firsthand observations, we turn to the particular case of COST Action networks. COST Actions are bottom-up science and technology networks, open to researchers and stakeholders with a duration of four years. They are active through a range of networking tools, such as workshops, conferences, training schools, short-term scientific missions (STSMs), and dissemination activities. However, COST does not fund research itself. COST Actions are managed by a Management Committee, in which all countries who have accepted the Action Memorandum of Understanding are represented by researchers relevant to the Action topic. The Management Committee (MC) is itself led by a leadership group, encompassing the Action Chair, Action Vice-Chair, the leaders of the different Action Working Groups and the STSM Coordinator. Each Action also has a Grant Holder, who is charged with the management of the financial and administrative side of the grant

An average COST Action can easily encompass over 200 participants, in somewhat different roles. At the "core" of the network are the researchers in the Action leadership, who are (relatively) heavily involved in the management of the network and can often be supposed to already have relatively strong ties to other Action participants. The other members of the Management Committee can be expected to be more varied in their integration in the Action network,. Finally, the experience of regular participants might depend on the networking tools they participated in (Meetings, Short-Term Scientific Missions and/or Training Schools), as well as on their frequency of participation. This leads to our first expectation:

Expectation I: Researchers in COST Action leadership positions might have a different view on the impact of COST Actions than other participants
COST Action participants do not only vary in the role they play in their respective Action networks, but also in the places they occupy in the broader system of research and innovation. COST Action participants differ in age from the mid-twenties all the way up to the high sixties. And while age might not be a perfect proxy for the career stage of individual researchers, on average we expect younger researchers to differ in their expectations and effective application of networking tools when compared to more advanced age cohorts. Researchers in an earlier career stage might have a different view on how COST Actions impact both their own research and the research in their field at-large. This leads to our second expectation:

Expectation II: Researchers who are earlier in their career might have a different perspective on impact than researchers who are more advanced in their career

Finally, COST Actions mostly involve researchers with a background in higher education and/or academic research, but they also incorporate participants from other backgrounds, notably from government agencies, from non-profit organisations or from business. Given the particular nature of academia and academic careers, academic participants might see the benefit and impact of COST Actions in a different light than other participants. This leads to our third expectation:

Expectation III: Researchers from non-academic backgrounds might have different perspectives on impact than researchers from an academic background

The fact that in COST Actions, researchers with very different backgrounds participate in networks with supposedly similar objectives renders these networks ideal "petri dishes" to gauge perspectives on "bottom-up" views on impact. All target groups as identified above participate in the same networks, with the same objectives ${ }^{1}$ and in a similar management and strategic context. Yet, different participants might come with different expectations to COST Actions, and they might also have different experiences when participating in the Action networks.

\section{METHOD}

In order to study differences in (perceived) perspectives on societal impact, we apply a Structural Topic Model (STM) approach. The STM approach finds it origins in political science, where it is used to study both cognitive and emotional attitudes towards political actors and objects - and the difference between those two. In broad terms, it allows distinguishing the topics which different target groups mention when asked the same open question, but it also allows to differentiate how different target groups talk about the same topic.

The technical background for Structural Topic Models can be consulted in Roberts et al. (2014) and Lucas et al. (2015). For the purpose of this paper, we will make an attempt to explain the method in layman's terms.

In general, pieces of text that pertain to the same topic will look like each other. The vocabulary of any language is limited, which means that when discussing a certain topic, an interlocutor will have to rely on repetition of certain words, or even sentence constructions. They will either repeat their own words or the words used by somebody else discussing the same topic. Hence, if certain words pop up in an unexpectedly high frequency in two separate texts, it is probable that these two texts so- 
mehow discuss the same topic ${ }^{2}$. This allows the classification, identification and eventual clustering of topic-relevant texts without necessary having to read these.

Two particular strategies can be followed in such a classification exercise. On the one hand, you can start out with established categories - for example, "texts concerning cats" and "texts concerning dogs". Each evaluated text is subsequently screened on words commonly associated with cats, and words commonly associated with dogs. This strategy has the main advantage that it will produce an outcome which goes in the lines of what you are exactly looking for. However, it also requires that you know the categories you want to distinguish upfront. This general approach is commonly known as supervised learning.

The opposite of supervised learning is (naturally) unsupervised learning. In unsupervised learning, the groups in which different objects are categorised are not a priori defined. Instead, the algorithm defines the groups itself, based upon observed similarities between groups. The Structural Topic Model is of this second category; based upon words occurring in a more than average frequency in several objects of study at the same time, "topics" are created. The Structural Topic Model allows the attribution of topics towards individual texts according to probability - for example, the text "Bacon rejected by critics" might be associated with both the topics of "cinema" and "food" according to a certain probability. Hence, in STM, a given body of text is not "definitely" grouped into a single topic, but rather has a distribution of probabilities of belonging to different topics.

The Structural Topic Model, finally, allows the testing of the different identified topics with metadata. In other words: are certain topics more prevalent than others in texts with a certain characteristic or background? This is crucial to see to what extent our expectations hold true, since we can differentiate between responses from our different target groups (participants in leadership positions, younger researchers and non-academic participants).

To conclude: the Structural Topic Model allows the identification of underlying topics in (unstructured) text data. It has proven its value in the context of analysing the flux of topics discussed on the internet in the run-up to the 2008 US presidential elections (Roberts et al., 2014). It is particularly a useful tool when a large amount of (unstructured) text data has to be analysed without strong a priori expectations. This makes it an interesting tool to test on researchers' attitudes towards impact of scientific activities; a topic hitherto only sparely studied.

\section{DATA}

In February-March 2018, survey company GfK Belgium executed a "Customer Satisfaction Survey" amongst around 43,000 participants and stakeholders in the COST framework. These participants had participated in the COST framework at least somewhere over the years 2016 and 2017, either as an Action participant, an Action main proposer or an Action grantholder. Of these, 14,384 participants responded for a response rate of $33 \%$.
In the Customer Satisfaction Survey, one particular open question was asked which touches upon (perceived) impacts of the COST Action networks. It was formulated as following:

"What was your direct benefit related to your participation in a COST Action?"

The question does not directly invoke impact, but this might not be a pressing issue; after all, the exact wording of "impact" might not be fully understood by all respondents, while "personal benefit" is relatively unequivocal in its meaning. A more crucial issue concerns the focus on "personal" in "personal benefit". Such an individual focus might induce the respondent to "automatically" think of impact on the strictly individual level, as opposed to broader, societal impact. Indeed, when analysing the results of this analysis, we should take this particular caveat into account.

In total 6168 respondents gave some kind of answer to this question (the question was optional - respondents could leave it blank). From these 6168, stop words (like "I", "can", "the", "are" etc.) were removed, and the remaining words were stemmed ${ }^{3}$. For the words remaining in the answers, we checked the number of answers in which the stemmed word appeared. Only words which appeared in at least $1 \%$ of the responses (i.e. in 62 responses) were retained. This has two advantages: it removes non-sensical answers (or answers not rendered in the English language) and it makes the eventual identification of the Topic Model easier, since many sparse observations are removed. 123 responses did not contain any stemmed word which reached the $1 \%$ threshold, and were therefore completely removed from the analysis, leaving 6045 responses for the identification of the Structural Topic Model.

The 6045 responses are as follows distributed over our variables of interest:

Table 1. Observed frequencies of independent variables.

\begin{tabular}{|l|l||l|l|}
\hline Younger researcher & 2013 & Leadership position & 636 \\
\hline Other researcher & 4032 & Other position & 5409 \\
\hline \hline Non-academic participant & 886 & Female & 2870 \\
\hline Academic participant & 5159 & Male & 3175 \\
\hline
\end{tabular}

A particularly sensitive step in the identification of Structural Topic Models is the number of topics to choose. The "unsupervised" method does not have a naturally defined number of topics, since the categories are not a priori known. For this particular run, we have chosen to limit the number of topics to 5 , which is a relatively modest number of topics (for example, Roberts et al. explored 20 topics). There are three reasons to do so.

First, unlike the Roberts paper, which concerned political campaigns, there is no temporal dimension to our analysis. In political campaigns, events of any kind can influence what people are talking about during the course of the campaign. We do not expect any such effect on perspectives of impact; at least not within the confines of our population of interest. Second, this paper is intended to give an indication of the extent to which perspectives on impact vary between target populations. For this end, a full description of all the possible topics discussed is not necessary, and a first step better involves less rather than more complexity.

\footnotetext{
1 This has not necessarily be the case, well understood. A text with a high frequency of the words "cat", "roof", "struggle", "worries" and "health" might be the story of a cat owner trying to get their pet out of an awkward situation, but it might also be a discussion of theatre night.

2 Stemming means that verbs, nouns, adjectives and adverbs with a similar origin (and supposedly similar meaning) are grouped together. For example, "collaboration", "collaborating" and "collaborative" are all grouped under the stem "collabor".
} 
In subsequent steps, a more complex model can still be studied. Third, we briefly looked into involving more (either 10 or 15 ) topics, but quickly realised that this would create a situation in which some topics started to overlap, at least on a contextual level.

\section{RESULTS}

Using the data and methods described above, we came to the following 5 topics. Each topic is described in Table 2 by the 15 words which are most exclusive to this topic (hence, they are relatively used the most in relation to this particular topic vis-à-vis other topics). Alternatively, we can find responses which are typical to the 5 distinguished topics. In Table 3, we display for each of the five topics two reactions which are "typical" of the topic at-large.

Table 2. 15 words most exclusive to structural topic, per identified topic.

\begin{tabular}{|c|c|}
\hline Topic 1 & 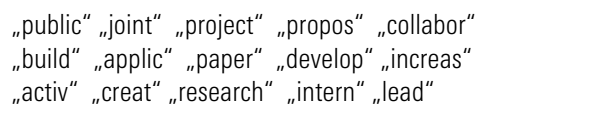 \\
\hline Topic 2 & 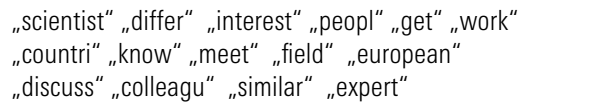 \\
\hline Topic 3 & 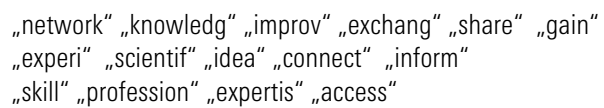 \\
\hline Topic 4 & 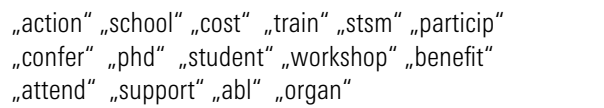 \\
\hline Topic 5 & 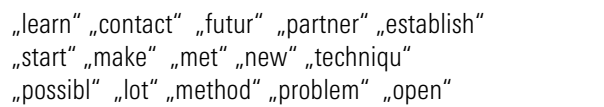 \\
\hline
\end{tabular}

As can be seen in Table 2 and Table 3, the topics identified have distinct characteristics. Topic 1 is strongly oriented towards outputs - papers and common projects, most prominently. Topic 2, to the contrary, is more oriented towards other researchers and meeting new people. Topic 3 is mostly oriented towards networking and sharing knowledge. Topic 4 is very concretely oriented towards the activities deployed within the framework of COST Actions and the benefits of being able to attend these activities. Topic 5 , finally, is somewhat more complicated, and seems to be a mix of different perspectives. This can either be due to respondents truly seeing different benefits of participating in COST Actions, or it can alternatively be due to the nature of our data collection (web-based surveys). In any case, topic 5 has mostly a general orientation on benefits of participating in a COST Action.

Table 3. 2 examples of two typical on-topic responses, per identified topic.

\begin{tabular}{|l|l|l|}
\hline $\begin{array}{l}\text { Topic 1 } \\
\text { (Output } \\
\text { orientation) }\end{array}$ & $\begin{array}{l}\text { New collaboration with } \\
2 \text { other researchers that } \\
\text { led to joint papers being } \\
\text { published and a new research } \\
\text { project externally funded }\end{array}$ & $\begin{array}{l}\text { An ongoing collaboration } \\
\text { that has resulted in few } \\
\text { publications and other } \\
\text { collaborations that resulted } \\
\text { with a EU grant proposal }\end{array}$ \\
\hline $\begin{array}{l}\text { Topic 2 } \\
\text { (People orientation) }\end{array}$ & $\begin{array}{l}\text { the interaction with experts } \\
\text { from different countries and } \\
\text { similar areas and the efforts } \\
\text { to search global solutions } \\
\text { at the European level }\end{array}$ & $\begin{array}{l}\text { Getting to know } \\
\text { groups working in the } \\
\text { same field from other } \\
\text { European countries }\end{array}$ \\
\hline
\end{tabular}

\begin{tabular}{|l|l|l|}
\hline $\begin{array}{l}\text { Topic 3 } \\
\text { (Knowledge } \\
\text { orientation) }\end{array}$ & $\begin{array}{l}\text { Networking, collaboration } \\
\text { development, expertise } \\
\text { improvement, exchange } \\
\text { of knowledge }\end{array}$ & $\begin{array}{l}\text { network, sharing } \\
\text { knowledge and data, } \\
\text { improvement of the quality } \\
\text { of research output }\end{array}$ \\
\hline $\begin{array}{l}\text { Topic 4 } \\
\text { (Activity orientation) }\end{array}$ & $\begin{array}{l}\text { It provides me chances to } \\
\text { go to international training } \\
\text { school, conference and another } \\
\text { institute for short term visiting. } \\
\text { Without the support from COST } \\
\text { Action, at least half of them } \\
\text { will be impossible. I appreciate } \\
\text { it very much. Thanks. }\end{array}$ & $\begin{array}{l}\text { I got invited into an ERA } \\
\text { net project proposal as a } \\
\text { result of participation in the } \\
\text { COST action. I have three } \\
\text { PhD students that benefited } \\
\text { greatly from participating } \\
\text { in workshops and training } \\
\text { schools organized by } \\
\text { the COST action. }\end{array}$ \\
\hline $\begin{array}{l}\text { Topic 5 } \\
\text { (General } \\
\text { orientation) }\end{array}$ & $\begin{array}{l}\text { Learned to use new } \\
\text { equipment and technology. } \\
\text { Met new colleagues with } \\
\text { whom there is a possibility } \\
\text { for future collaborations. }\end{array}$ & $\begin{array}{l}\text { I met new colleagues } \\
\text { and started new } \\
\text { collaborations, which are } \\
\text { exciting new directions. }\end{array}$ \\
\hline
\end{tabular}

In a second step, we test our expectations as formulated earlier on by seeing whether the tendency to talk about the five respective topics we identified is related to background characteristics of the respondents. We do so by regressing, for each topic, the respective chance that a body of text belongs to this particular topic onto the three independent variables of interest, which correspond to the three expectations (concerning younger researchers, non-academic researchers and researchers in leadership positions) as formulated in the Introduction. Additionally, as a control variable, we include gender. The four independent variables are all coded as binary variables: researcher younger than 40 years vs researcher of 40 years or older, researcher with a non-academic background vs researcher with an academic background, researcher in a leadership position vs researcher in another position, female researcher vs male researcher.

In the case of age, gender and professional background, the characteristics have been self-reported by the respondents through their e-COST (the COST online platform) profile. In the case of professional background, we have observed some misreporting (e.g. somebody from academia reporting that they are from a "governmental agency", which is non-academic). Hence, estimators might be slightly biased for this particular variable, although we do not have a strong a priori expectation concerning a potential direction of this bias; some underestimation of effects might occur, in any case.

We will consider the five different topics individually.

Table 4. OLS regression on Topic 1: Output orientation.

\begin{tabular}{|l|l|l|l|}
\hline Independent variable & Coefficient & Std Error & Significance \\
\hline Intercept & 0.23354 & 0.00444 & $* * *$ \\
\hline Younger researcher & -0.03378 & 0.00456 & $* * *$ \\
\hline Non-academic & -0.01725 & 0.00596 & $* *$ \\
\hline Leadership position & 0.02894 & 0.00776 & $* * *$ \\
\hline Female researcher & -0.00792 & 0.00498 & N/A \\
\hline
\end{tabular}

Concerning output-orientation, we observe substantial differences between the groups of interest. Researchers in leadership positions tend to be more oriented towards outputs like common projects and proposals. For both younger researchers and non-academic participants, however, this tends to be less the case. Possibly this is due to younger researchers not yet being in the position of seniority which enables effective participation as co-leaders of major projects in Rgl. For non-academic participants, common projects might sometimes be less attractive due to the academic focus of some research projects. 
Table 5. OLS regression on Topic 2: People orientation.

\begin{tabular}{|l|l|l|l|}
\hline Independent variable & Coefficient & Std Error & Significance \\
\hline Intercept & 0.24681 & .00408 & $* * *$ \\
\hline Younger researcher & -0.02013 & .00551 & $* * *$ \\
\hline Non-academic & 0.01009 & .00643 & N/A \\
\hline Leadership position & -0.01951 & .00476 & $* *$ \\
\hline Female researcher & 0.00208 & .00844 & N/A \\
\hline
\end{tabular}

Concerning orientation towards meeting other people, we see that both researchers in leadership positions and younger researchers are less likely to veer towards this particular topic in their response. For researchers in leadership positions, this might be explained by the fact that they possibly already have the right contacts, and do not have to use COST Action networks to create such links. For younger researchers, this phenomenon is slightly more puzzling; it would seem to make sense that younger researchers still have to build up their network. It might be that younger researchers are more looking for the actual activities deployed in COST Actions than for the people they meet during these activities.

Table 6. OLS regression on Topic 3: Knowledge orientation.

\begin{tabular}{|l|l|l|l|}
\hline Independent variable & Coefficient & Std Error & Significance \\
\hline Intercept & 0.19901 & .00306 & *** \\
\hline Younger researcher & -0.00162 & .00420 & N/A \\
\hline Non-academic & 0.01940 & .00581 & *** \\
\hline Leadership position & -0.00871 & .00371 & $*$ \\
\hline Female researcher & -0.00408 & .00646 & N/A \\
\hline
\end{tabular}

Concerning orientation towards gaining and sharing (general) knowledge, we see that participants with a non-academic background are more likely to refer to this topic when describing their benefit of participating in a COST Action network. Researchers in leadership positions are, on the other hand, less likely to refer to such benefits. Again, we could say that for researchers in leadership positions, access to knowledge might be less "attractive", since they are already in the centre of this body of knowledge, figuratively speaking. For non-academic participants, we could hypothesise that access to knowledge might be particularly appealing since they are not necessarily in touch with academic knowledge on a daily basis. COST Actions, which can incorporate up to 300 researchers from different backgrounds and disciplines can, in this respect, form a "glossary of knowledge" for outside researchers.

Table 7. OLS regression on Topic 4: Activity orientation.

\begin{tabular}{|l|l|l|l|}
\hline Independent variable & Coefficient & Std Error & Significance \\
\hline Intercept & 0.15380 & 0.00424 & *** \\
\hline Younger researcher & 0.05690 & 0.00543 & $* * *$ \\
\hline Non-academic & -0.02054 & 0.00699 & $* *$ \\
\hline Leadership position & 0.01543 & 0.00532 & $* *$ \\
\hline Female researcher & 0.00563 & 0.00863 & N/A \\
\hline
\end{tabular}

Concerning orientation towards Actions' activities, we see that researchers in leadership positions and, in particular, younger researchers are more likely to indicate an orientation towards activities deployed by COST Actions. Non-academic participants are, on the other hand, less likely to mention this topic. The tendency of younger researchers to mention this topic is particularly pronounced. A potential reason for this remarkable result is that younger researchers are more oriented towards gaining skills, which are transmitted through COST Action activities like Short-Term Scientific Missions and Training Schools, although other hypotheses might equally be offered.

Table 8. OLS regression on Topic 5: General orientation.

\begin{tabular}{|l|l|l|l|}
\hline Independent variable & Coefficient & Std Error & Significance \\
\hline Intercept & 0.16710 & 0.00365 & $* * *$ \\
\hline Younger researcher & -0.00195 & 0.00463 & N/A \\
\hline Non-academic & 0.00866 & 0.00645 & N/A \\
\hline Leadership position & -0.00195 & 0.00436 & N/A \\
\hline Female researcher & -0.00920 & 0.00754 & N/A \\
\hline
\end{tabular}

Finally, the general orientation does not correlate with any of our variables of interest. This is not a particularly surprising finding; there is no particular reason why one target group would be less (or more) likely to mention particular benefits of participating in COST Actions.

\section{CONCLUSION}

We started this paper with the assessment that the concept of "societal impact" has come to play a more dominant role in assessing the value of research and innovation, especially from the perspective of public funding. We equally observed that there is, as yet, no clear convergence on how to define or further conceptualise "societal impact". In order to make a (very modest) step towards a bit more clarification, we applied a "bottom-up" perspective on the question, by asking researchers themselves what they saw personally as an impact of their involvement in research projects.

One important conclusion is that it depends on who you ask: in the context of COST Action networks, we observed differences in perspectives between different participants in the projects. Perceived impact depends on the position in the COST Action, with researchers in the core having different perspectives than other researchers, but the perceived impact also varies with career stage and with the background of participants.

Notably, participants with a non-academic background turned out to be less oriented towards projects and collaborations, and more oriented towards general knowledge sharing. This is a particularly intriguing result given that one particular strain on "societal impact" stresses the need for "productive interactions" as the basis of achieving this impact (de Jong et al., 2014). The orientation of non-academic participants of COST Actions towards knowledge sharing seems to confirm this notion. Yet, impact evaluation still has a - somewhat understandable - orientation towards easy-to-measure, direct results of impact (Donovan, 2007). It might actually well be that the actual pathways towards societal impact - by opening channels between researchers and societal actors - are not fully grasped by this "traditional" orientation towards concrete outputs and results.

From a broader perspective, we can maybe see some seeds of a more encompassing way of assessing impact. The four specific topics we identified (beside the "general" topic) all point towards specific aspects of COST Actions: the individuals involved (the "people" orientation), the activities deployed (the "activity" orientation), the common projects spinning 
off from the Action (the "project" orientation) and the general topic of the Action (the "knowledge" orientation). In other words, the perceived benefits of participation in a COST Action do, in the eyes of the participants, originate from a mix of different aspects of the Action they participate in. Hence, although this is still a very tentative conclusion, it might be worthwhile to evaluate the impact of research projects - including Actions - on different accounts. Spin-off projects and results can surely play an important role in this evaluation, but so might whether the project was broad and inclusive concerning the partners involved, whether adequate activities were deployed in the scope of the project and whether the topic and the general set-up of the project stimulated an exchange of knowledge and practices. All of these aspects seem at least to play some role in making sure society ultimately benefits from research.

Of course, there are some limitations to this paper. We asked participants of one specific instrument in the landscape of R\&l funding to formulate their thoughts on the benefits of participating in this benefit. Given that this instrument - COST Action - revolves around research networking rather than research itself, we should be careful with extrapolating the results to conclusions about the impact of R\&l funding atlarge. Moreover, the method deployed in this study was intentionally explorative, and follow-up research would still have to confirm - or amend - the initial patterns observed in our study. Nonetheless, the finding that (societal) impact of research might be approached from very different perspectives looks relatively robust, and surely needs more consideration in future studies. In this respect impact might be much like beauty: it is all in the eye of the beholder.

\section{REFERENCES}

Bell, S., Shaw, B. and Boaz, A. (2011). Real-world approaches to assessing the impact of environmental research on policy. Research Evaluation, 20:227.

Bornmann, L. (2013). What Is Societal Impact of Research and How Can It Be Assessed? A Literature Survey. Journal of the American Society for Information Science and Technology, 64:217.

Bozeman, B. and Sarewitz, D. (2005). Public values and public failure in US science policy. Science and Public Policy, 32:119.

De Jong, S., Barker, K., Cox, D., Sveindottir, T. and van den Besselaar, P. (2014). Understanding societal impact through productive interactions: ICT research as a case. Research Evaluation, 23:89.

Donovan, C. (2007). The qualitative future of research evaluation. Science and Public Policy, 2007:585.

Etzkowitz, H. and Leydesdorff, L. (2000). The dynamics of innovation: from National Systems and "Mode 2" to a Triple Helix of university-industry-government relations. Research Policy, 29:109.

Fowler, J. and Aksnes, D. (2007). Does self-citation pay? Scientometrics, 72:427.

Gibbons, M. (2000). Mode 2 society and the emergence of context-sensitive science. Science and Public Policy, 27:159.
Hessels, L.K. and van Lente, H. (2008). Re-thinking new knowledge production: A literature review and a research agenda. Research Policy, $37: 740$.

Hicks, D., Wouters, P., de Rijcke, S. and Rafols, I. (2015). The Leiden Manifesto for research metrics. Nature, 520:431.

Holbrook, J.B. and Frodeman, R. (2011). Peer review and the ex-ante assessment of societal impacts. Research Evaluation, 20:239.

Leydesdorff, L. and Etzkowitz, H. (1998). The Triple Helix as a model for innovation studies. Science and Public Policy, 25:195.3

Lucas, C., Nielsen, A., Robets, M.E., Stewart, B.M., Storer, A. and Tingley, D. (2015). Computer-Assisted Text Analysis for Comparative Politics. Political Analysis, 23:254.

Morton, S. (2015). Progressing research impact assessment: A 'contributions' approach. Research Evaluation, 24:405.

Mostert, S., Ellenbroek, S., Meijer, I., van Ark, G. and Klasen, E. (2010). Societal output and use of research performed by health research groups. Health Research Policy and Systems, 8: 30.

Nightingale, P. and Scott, A. (2007). Peer review and the relevance gap: Ten suggestions for policy-makers. Science and Public Policy, 34:543.

Ravetz, J.R. (1999). What is Post-Normal Science. Futures, 31:647.

Roberts, M.E., Stewart, B.M., Tingley, D., Lucas, C., Leder-Luis, J. Kushner Gadarian, S, Albertson, B. and Rand, D.G. (2014). Structural Topic Models for Open Ended Survey Responses. American Journal of Political Science, 58:1064.

Sarewitz, D. and Pielke, A.J. (2007). The neglected heart of science policy: reconciling supply of and demand for science. Environmental Science \& Policy, 10:5.

Spaapen, J. and van Drooge, L. (2011). Introducing 'productive interactions' in social impact assessment. Research Evaluation, 30:211.

Van der Weijden, I., Verbree, M. and van den Besselaar, P. (2012). From bench to bedside: The societal orientation of research leaders: The case of biomedical and health research in the Netherlands. Science and Public Policy, 39:285.

\section{AUTHOR}

\section{ELWIN REIMINK}

Data \& Impact Analysis Officer, COST Association, Avenue Louise 149, Brussels, Belgium

E: elwin.reimink@cost.eu 